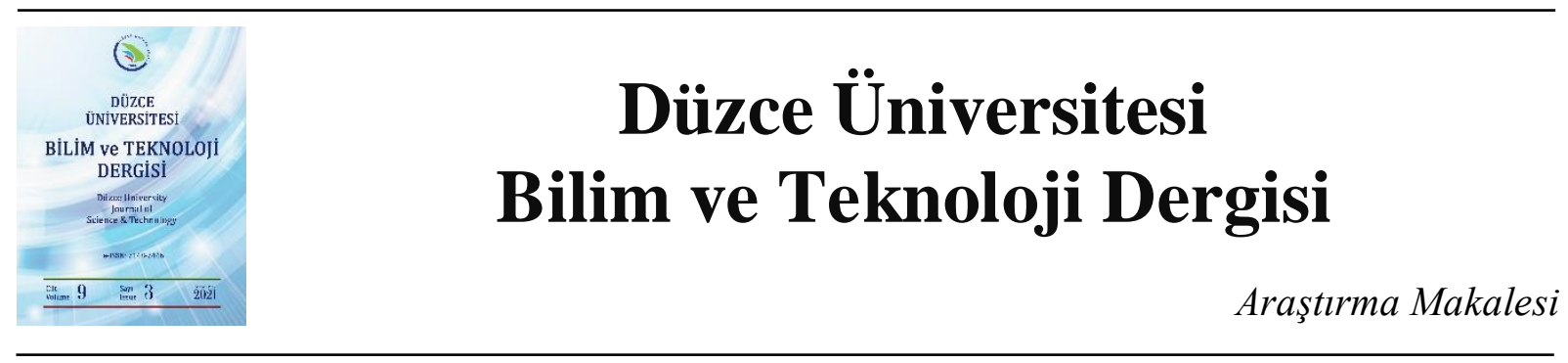

\title{
Çelik Gömmeli Kompozit Kolonların Sonlu Elemanlar Analizi ile Sayısal Karşılaştırılması
}

\author{
Kıvanç TAŞKIN ${ }^{\mathrm{a}, *}$, (D) Fethullah USLU ${ }^{\mathrm{b}}$ \\ ${ }^{a}$ İnşaat Mühendisliği Bölümü, Mühendislik Fakültesi, Eskişehir Teknik Üniversitesi, Eskişehir, TÜRKIYE \\ ${ }^{b}$ Inşaat Mühendisliği Bölümü, Mühendislik Fakültesi, Kütahya Dumlupınar Üniversitesi, Kütahya, TÜRKIYE \\ * Sorumlu yazarin e-posta adresi: kivanct@eskisehir.edu.tr
}

DOI: $10.29130 /$ dubited. 884144

\begin{abstract}
ÖZET
$\mathrm{Bu}$ çalışma, çelik gömmeli kompozit kolonların, beton dayanımı ile boyuna donatı oranının değişimine göre eksenel basınç kuvveti etkisindeki davranışını açıklamaktadır. Bu sebeple, dört farklı boyuna donatı ( $\phi 16-20-24-$ $30)$, beton sınıfı (C40-50-60-70) ve yapısal çelik yüzdesi (\%1-2-4-8) için on altı farklı grup olmak üzere toplamda altmış dört model oluşturulmuştur. Her bir model için önce Çelik Yapıların Tasarım, Hesap ve Yapımına Dair Esasları (ÇYTHYE-2016) ve American Institute of Steel Construction (AISC 360-16) standartlarında tanımlanan eksenel kuvvet-moment etkileşim grafikleri elde edilmiştir. Bu grafiklerden her farklı grup için taşıyabileceği maksimum eksenel basınç kuvveti hesaplanmıştır. Oluşturulan modellerdeki beton, yapısal çelik ve boyuna donatıya ait eksenel basınç kuvvetleri, yerdeğiştirmeler, şekil değiştirmeler, akma noktaları ANSYS sonlu elemanlar programı kullanılarak elde edilmiştir. Beton basınç değeri arttıkça eksenel taşıma kapasitesinin arttığını fakat eğilme momenti değerinin birbirlerine çok yakın gerçekleştiği ve sadece çelik oranı değiştirildiğinde ise eksenel basınç dayanımının sabit kaldığı, eğilme moment değerlerinin arttığı görülmüştür. Yönetmeliklerde verilen ampirik ifadeler kullanılarak hesaplanan en büyük eksenel basınç kuvveti değeri ile ANSYS'den elde edilen değerler birbirleri ile uyumlu çıkmışlardır. Analizlerin göstermiş olduğu en önemli sonuç çelik gömmeli kesitlerde kullanılan çelik profilin taşıma kapasitesinin tamamının kullanılabildiğidir.
\end{abstract}

Anahtar Kelimeler: Kompozit Kolon, Sonlu Eleman Analizi, Donatı Oranı, Eksenel Basınç Kuvveti

\section{Numerical Comparison of Concrete Encased Steel Composite Columns with Finite Element Analysis}

\begin{abstract}
In this study, four prototypical design examples were developed to investigate the behavior and design requirements for concrete-encased composite columns. All columns are square with a fixed transverse reinforcing bar arrangement but with different encased shapes with structural steel ratios of \%1, 2, 4 and 8 . The longitudinal reinforcing bars were chosen four different diameters of $\phi 16, \phi 20, \phi 24$ and $\phi 30$. Four concrete strengths used fck $=40,50,60$ and $70 \mathrm{MPa}$ represent low, medium, and high-strength concrete, respectively. Firstly, for each model, moment-axial force interaction graphs defined in Design, Calculation, and Construction of Steel Structures (ÇYTHYE-2016) and American Institute of Steel Construction (AISC 360-16) standards were obtained. The maximum axial compression force it can carry for each different group has been calculated from these graphs. The axial pressure forces, displacements, strains, yield points of concrete, structural steel, and longitudinal reinforcement in the created models were obtained using the ANSYS finite element program. It was observed that as the concrete pressure value increased, the axial carrying capacity increased. Still, the bending moment value was very close to each other, and when only the steel ratio was changed, the bending moment values where the axial compressive strength remained constant. The maximum axial pressure force value calculated using the empirical expressions given in the regulations and the values obtained from ANSYS are compatible with each
\end{abstract}


other. The most important result of the analysis is that the steel profile used in steel embedded sections can be used ultimately.

\section{GIRIS}

Dayanım ve süneklik açısından iyi bir davranış sergileyen kompozit yapı tasarımı son yıllarda gelişmiş ülkelerde çoğunlukla ofis binaları, ticari binaları, park alanları ve köprüler için giderek daha fazla kullanılmaktadır. Yüksek yapılarda, kolonlarda ortaya çıkan kesit tesirleri göz önüne alındığında, yüksek değerlere sahip eksenel yükleri taşıyacak kesitler ancak ekonomik olarak kompozit tasarımla mümkün olmaktadır. Kompozit elemanlar sunduğu avantajlara rağmen sismik tasarımda nadiren kullanılmaktadır. Bunun başlıca nedenleri bir yandan yeterli deneyimin, vasıflı işçi ve uygun ekipmanı olmaması diğer yanda ise bu yapıların tasarım için uygun standartların son yıllara kadar bulunmaması olarak sıralanabilir. Ülkemizde 2016 yılında yürürlüğe giren Çelik Yapıların Tasarım, Hesap ve Yapımına Dair Esasları (ÇYTHYE) yönetmeliğinde [1] sismik alanlar için kompozit yapıların tasarlanması için genel prensipleri ve performans kurallarını sunmaktadır.

Hem çelik hem de betonarmenin bir arada kullanılması sebebi ile kolonların sünekliğinin betonarme kolonlara göre daha fazla olacaktır. Kompozit kolonlar, geleneksel betonarme kolonlara göre daha küçük bir en kesite sahip olduklarından dolayı daha ekonomiktirler. Bunun yanında, eksenel yük taşıma kapasiteleri de yüksektir. Sıradan çelik kolon ile karşılaştırıldığında korozyon ve burkulmaya karşı daha dayanımlıdırlar. Çelik profilin burkulmasını önleyerek taşıma kapasitesini arttıracak olan kompozit kolon tipi çelik gömmeli kompozit kesittir.

Çelik gömmeli kompozit kolonlar, betonarme ve çelik elemanlara göre sahip oldukları yüksek taşıma kapasitesi sebebi ile genellikle yüksek katlı yapıların bodrum katlarında, tüplü sistemlerin çekirdek kısmında, yeraltına yapılan otopark vb. yapılarda kullanılmaktadırlar. Çelik gömmeli kompozit kolonlarda çelik elemanın başlıkları arasına kısmi gömülmüş veya tam gömülü olarak imal edilebilirler. Sismik davranış ve yük taşıma kapasitesi açısından betona çelik profil gömülü kompozit elemanlar ile oluşturulmuş çerçeve taşıyı sistemlerin betonarme sistemlere göre daha küçük kesitlere sahip olmalarına rağmen daha iyi performans davranışı sergilemektedirler.

Tasarlanan kompozit elemanları oluşturan beton, yapısal çelik ve betonarme çeliğini malzeme davranışları birbirlerinden farklıdır. Taşıma kapasiteleri ile şekil değiştirme değerleri bu farklılıkları oluşturmaktadır. Bu da farklı malzemelerin doğru şekilde modellenmesi ve analiz edilmesi gerekliliğini ortaya çıkarmıştır. Son yıllarda gelişen bilgisayar teknolojisi ve buna paralel özellikle matematik alanındaki gelişmeler sonlu elemanlar yöntemini daha rahat kullanılır hale getirmiştir. Sonlu elemanlar programlarından biri olan ANSYS [2] özellikle kompozit yapıların tasarımında üç boyutlu doğrusal olmayan davranışa dayalı olarak yapıyı oluşturan elemanların (beton, çelik, donatı) davranışlarını gerilme, şekil değiştirme, uç yerdeğiştirmeleri açısından rahatlıkla analiz etmektedir [3]-[4]. Betonarme ve çelik yapıları gerilme dağılımları (kontur çizgileri), çatlak oluşumları, deformasyonlar ve yük taşıma kapasitesi değerlerini hesaplayacak şekilde birçok analitik ve nümerik modeller vardır [5]-[9]. Ayrıca çelik gömmeli kompozit kolonlarda farklı narinlik oranları, çelik kesitleri, beton ve çelik dayanımlarına sahip kompozit kolonlar üzerine analitik çalışmalar yapmışlardır [10]-[16].

Bu çalışmada, çelik gömmeli kompozit kolonların davranışını incelemek için ANSYS sonlu eleman programında model oluşturularak doğrusal olmayan analiz yapılmıştır. Yapılan analizlerden elde edilen değerler ile yönetmeliklerden elde edilen değerler kıyaslanmıştır. Ayrıca çelik gömmeli kesitlerde kullanılan çelik profilin taşıma kapasitesi araştırılmıştır. 


\section{MATERYAL VE YÖNTEM}

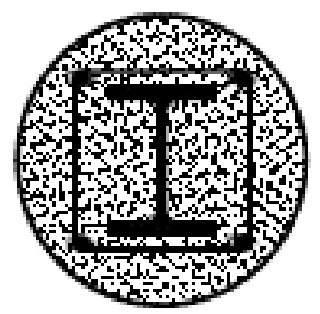

a)

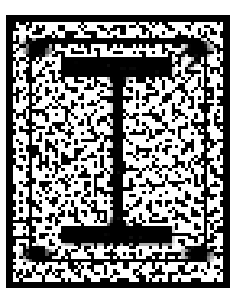

b)

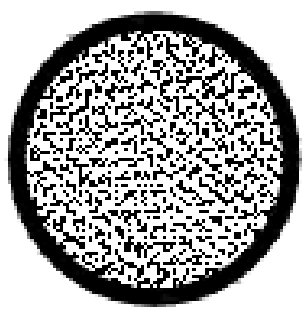

c)

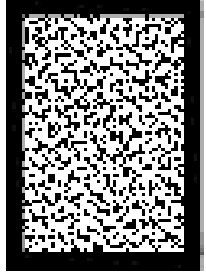

d)

Şekil 1. Tipik kompozit kolonlar [1]

Ülkemizde 2016 yılında yürürlüğe giren ÇYTHYE [1] yönetmeliği kullanılmaktadır. İlgili yönetmeliğin Bölüm 12'de yer alan kompozit kolon elemanlarına ait tasarım hesabı yer almaktadır. Yönetmelikte yer alan tipik kompozit kolonlar elemanlar Şekil 1'de gösterilmektedir.

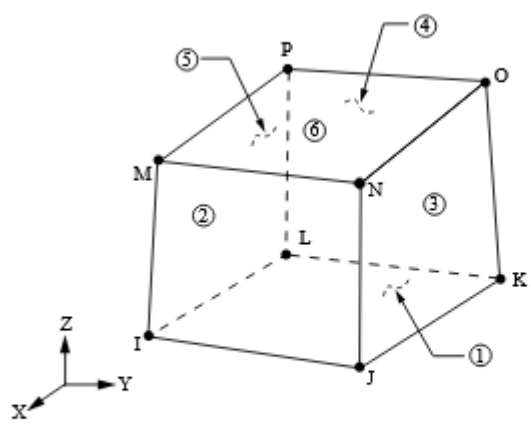

a)

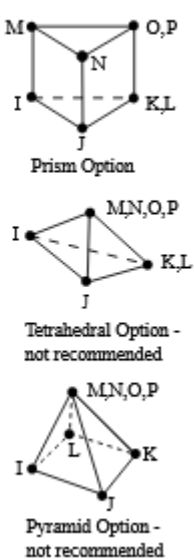

not recommended

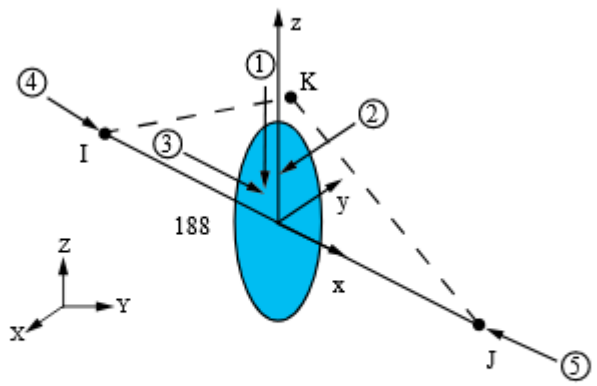

b)

Şekil 2. a) SOLID185 b) BEAM188 elemanlarına ait geometrik özellikler [2]

Çelik gömmeli kompozit kolonların modellenmesinde, ANSYS programı yaygın olarak kullanılmaktadır. ANSYS programında öncelikle örnek problemin geometrisi ve malzeme özellikleri tanımlanmalıdır. ANSYS eleman kütüphanesinde yapısal çelik, donatı çeliği ve beton için üç ayrı malzeme özellikleri ile birlikte uygun eleman seçimi yapılmalıdır.

Yapısal çelik için ANSYS programında SOLID185 eleman1, enine ve boyuna donatı çeliği için ise BEAM188 elemanı kullanılmıştır (Şekil 2). Beton malzemeler için çok farklı parametrik modellemelerle çalışmalar yapılmıştır. ANSYS Mechanical APDL'de beton modellerinin oluşturulmasında yaygın olarak SOLID65 eleman tipi kullanılmaktadır [3]-[4],[8]. Eğer, beton gibi özel bir malzeme için ise kullanılacak eleman SOLID65 olmalıdır. Hem malzeme hem de geometri bakımından lineer olmayan davranış modellendiğinden SOLID65 elemanı uygun olmayacaktır. SOLID185, genel amaçlı üç boyutlu malzemenin lineer davranışının modellenebileceği bir katı eleman tipidir. Bunun sonucunda SOLID185 elemanı seçilerek analizler tamamlanmıştır. Bu eleman tipi Workbench ara yüzünde seçili halde olmayıp, malzeme isimlendirmesi şeklinde "CONCRETE NL" adıyla bulunmaktadır. Literatürde beton modellemesi için SOLID185 elamanı birçok çalışmada kullanılmış ve başarılı sonuçlar verdiği görülmüştür, [17]-[21].

ANSYS eleman kütüphanesinde bulunan SOLID185, yüksek mertebeli 3 boyutta 8 düğüme sahip kat1 elemanı ve BEAM188 ise 3 boyutta 2 dügüme sahip kiriş elemanıdır. Bu elemanlar her bir düğüm 
noktalarında $\mathrm{x}, \mathrm{y}$ ve $\mathrm{z}$ doğrultusunda yerdeğiştirme serbestliği vardır [2]. Hem güvenilir sonuçlar hem de daha az hesaplama süresi sağlayan uygun bir ağ seçmek için farklı ağ boyutları denenmiştir. Burada maksimum çelik için $10 \mathrm{~mm}$, beton için ise $40 \mathrm{~mm}$ ağ boyutu seçilerek sonuçların yakınsadı̆̆ görülmüştür. Kompozit kolon için örnek ağ modeli verilmiştir (Şekil 3).

ANSYS programında oluşturulan sonlu eleman modelinde çelik, beton, boyuna ve enine donat1 elemanlarına uygun malzeme özellikleri tanımlanmıştır. Bu elemanların davranışını incelemek üzere, farklı yapısal çelik alan yüzdeleri (\%1-2-4-8), boyuna donatı çapları ( $\phi 16-20-24-30)$ ve beton sinıfları (C40-50-60-70) için on altı farklı grup olmak üzere toplamda altmış dört model oluşturularak parametrik bir çalışma yapılmıştır. Bu parametrik çalışmada çelik gömmeli kompozit kolonların yüksekliği $3000 \mathrm{~mm}$, kesit genişliği 600x600 mm ve enine donatı çapı $\phi 10 / 200 \mathrm{~mm}$ olarak modellenmiştir.

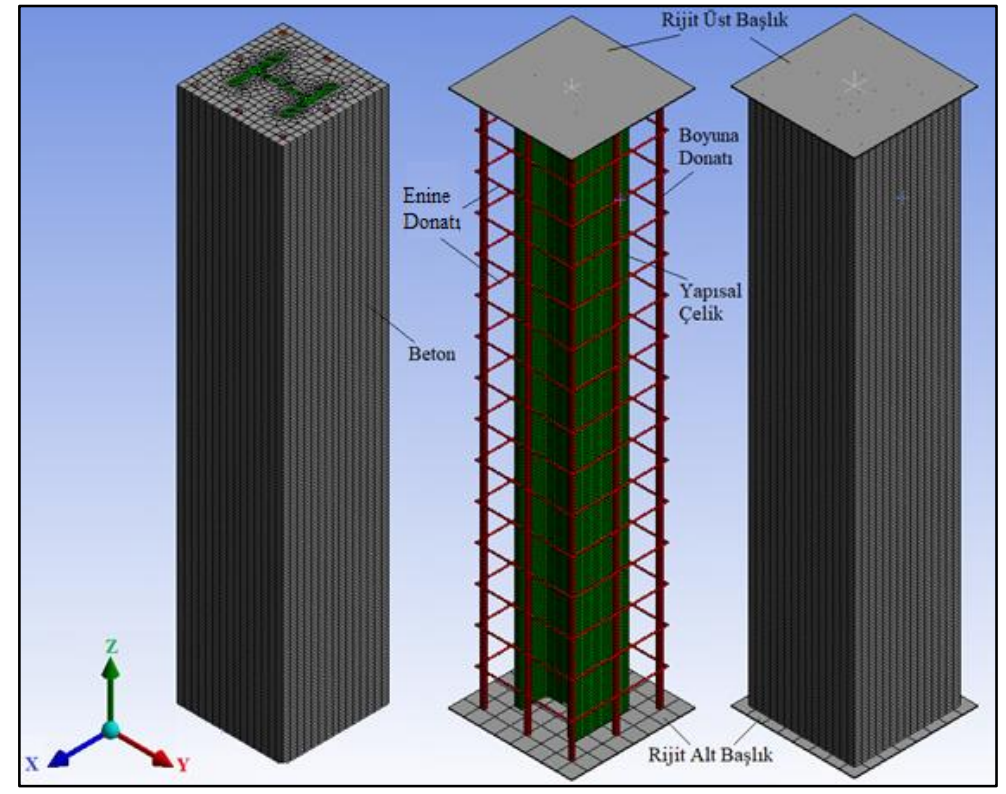

Şekil 3. Çelik gömmeli kompozit kolon modeli

Her bir model için önce ÇYTHYE [1] ve AISC [22] standartlarında tanımlanan eksenel kuvvet ve eğilme momenti karşılıklı etkileşim diyagramların davranışı incelenmiştir. Buradan elde edilen grafiklerden her farklı grup için taşıyabileceği maksimum eksenel basınç kuvveti belirlenmiştir. Oluşturulan modellerdeki beton, yapısal çelik ve boyuna donatıya ait eksenel basınç kuvvetleri, yerdeğiştirmeleri, şekil değiştirmeleri, gerilmeleri (Von mises) ve akma noktalarını ANSYS sonlu elemanlar programı kullanılarak elde edilmiştir. ANSYS sonlu elemanlar program analizinden elde edilen kolon dayanımları (eksenel taşıma kapasiteleri), ÇYTHYE [1] yönetmeliği kullanılarak hesaplanan tasarım dayanımları ile karşılaştırılmıştır.

Parametrik çalışmada çelik gömmeli kompozit kolonların her iki ucu da mafsallı olarak tanımlanmıştır. Şekil 3 'te gösterilen ANSYS modelinde üst levhasının dış yüzeyinin z yönündeki yerdeğiştirmesine ve $\mathrm{x}$-y ekseni etrafinda dönmesine izin verilmiştir. Alt levhanın dış yüzeyinin yerdeğiştirmeleri ise sınırlandırılmıştır ve $x-y$ ekseni etrafında dönmesine izin verilmiştir. Kompozit kolona düşey olarak yük artışları uygulanarak sistem göçene kadar doğrusal olmayan (nonlinear) analizler yapılmıştır. 


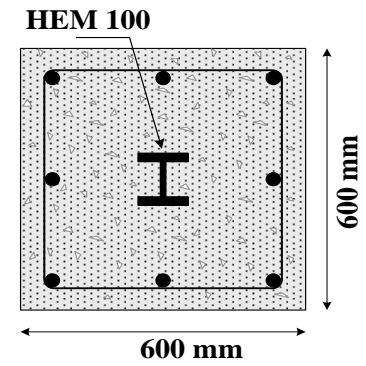

a)

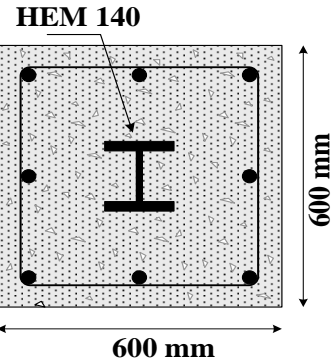

b)
HEM 220

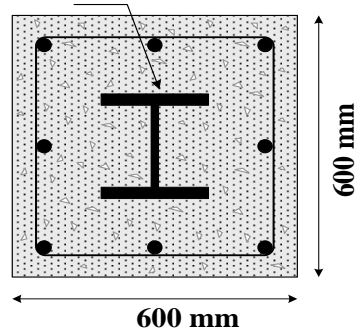

c)

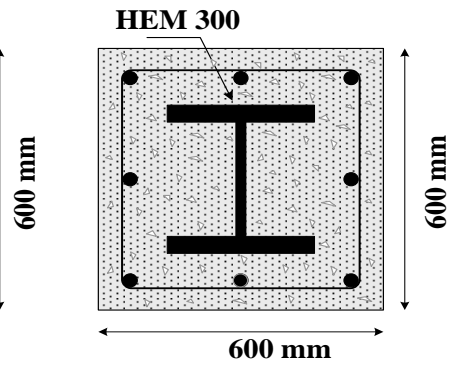

d)

Şekil 4. Çelik gömmeli kompozit kolon tipler

Çelik gömmeli kompozit kolon tipleri Şekil 4'deki gibi modellenmiştir. Parametrik çalışma kapsamında oluşturulan toplam altmış dört adet çelik gömmeli kompozit kolonlara ait malzeme özellikleri Tablo 1'de verilmiştir.

Tablo 1. Parametrik çalışmada çelik gömmeli kompozit kolonların malzeme özellikleri

\begin{tabular}{|c|c|c|c|c|c|c|c|c|c|c|c|}
\hline Grup & Numune & Çelik kesit & As/Ag & $\begin{array}{c}\text { Boyuna } \\
\text { Donatı } \\
(\mathrm{mm})\end{array}$ & $\begin{array}{c}\text { fck } \\
(M P a)\end{array}$ & Grup & Numune & $\begin{array}{l}\text { Çelik } \\
\text { kesit }\end{array}$ & As/Ag & $\begin{array}{c}\text { Boyuna } \\
\text { Donatı } \\
(\mathrm{mm})\end{array}$ & $\begin{array}{c}\text { fck } \\
(M P a)\end{array}$ \\
\hline \multirow{4}{*}{ G1 } & N1 & HEM 100 & $1 \%$ & 16 & 40 & \multirow{4}{*}{ G9 } & N33 & HEM 220 & $4 \%$ & 16 & 40 \\
\hline & $\mathrm{N} 2$ & HEM 100 & $1 \%$ & 16 & 50 & & N34 & HEM 220 & $4 \%$ & 16 & 50 \\
\hline & N3 & HEM 100 & $1 \%$ & 16 & 60 & & N35 & HEM 220 & $4 \%$ & 16 & 60 \\
\hline & N4 & HEM 100 & $1 \%$ & 16 & 70 & & N36 & HEM 220 & $4 \%$ & 16 & 70 \\
\hline \multirow{4}{*}{$\mathrm{G} 2$} & N5 & HEM 100 & $1 \%$ & 20 & 40 & \multirow{4}{*}{ G10 } & N37 & HEM 220 & $4 \%$ & 20 & 40 \\
\hline & N6 & HEM 100 & $1 \%$ & 20 & 50 & & N38 & HEM 220 & $4 \%$ & 20 & 50 \\
\hline & N7 & HEM 100 & $1 \%$ & 20 & 60 & & N39 & HEM 220 & $4 \%$ & 20 & 60 \\
\hline & N8 & HEM 100 & $1 \%$ & 20 & 70 & & N40 & HEM 220 & $4 \%$ & 20 & 70 \\
\hline \multirow{4}{*}{ G3 } & N9 & HEM 100 & $1 \%$ & 24 & 40 & \multirow{4}{*}{ G11 } & N41 & HEM 220 & $4 \%$ & 24 & 40 \\
\hline & N10 & HEM 100 & $1 \%$ & 24 & 50 & & $\mathrm{~N} 42$ & HEM 220 & $4 \%$ & 24 & 50 \\
\hline & N11 & HEM 100 & $1 \%$ & 24 & 60 & & N43 & HEM 220 & $4 \%$ & 24 & 60 \\
\hline & N12 & HEM 100 & $1 \%$ & 24 & 70 & & N44 & HEM 220 & $4 \%$ & 24 & 70 \\
\hline \multirow{4}{*}{ G4 } & N13 & HEM 100 & $1 \%$ & 30 & 40 & \multirow{4}{*}{ G12 } & $\mathrm{N} 45$ & HEM 220 & $4 \%$ & 30 & 40 \\
\hline & N14 & HEM 100 & $1 \%$ & 30 & 50 & & N46 & HEM 220 & $4 \%$ & 30 & 50 \\
\hline & N15 & HEM 100 & $1 \%$ & 30 & 60 & & N47 & HEM 220 & $4 \%$ & 30 & 60 \\
\hline & N16 & HEM 100 & $1 \%$ & 30 & 70 & & N48 & HEM 220 & $4 \%$ & 30 & 70 \\
\hline \multirow{4}{*}{ G5 } & N17 & HEM 140 & $2 \%$ & 16 & 40 & \multirow{4}{*}{ G13 } & N49 & HEM 300 & $8 \%$ & 16 & 40 \\
\hline & N18 & HEM 140 & $2 \%$ & 16 & 50 & & N50 & HEM 300 & $8 \%$ & 16 & 50 \\
\hline & N19 & HEM 140 & $2 \%$ & 16 & 60 & & N51 & HEM 300 & $8 \%$ & 16 & 60 \\
\hline & N20 & HEM 140 & $2 \%$ & 16 & 70 & & N52 & HEM 300 & $8 \%$ & 16 & 70 \\
\hline \multirow{4}{*}{ G6 } & N21 & HEM 140 & $2 \%$ & 20 & 40 & \multirow{4}{*}{ G14 } & N53 & HEM 300 & $8 \%$ & 20 & 40 \\
\hline & N22 & HEM 140 & $2 \%$ & 20 & 50 & & N54 & HEM 300 & $8 \%$ & 20 & 50 \\
\hline & N23 & HEM 140 & $2 \%$ & 20 & 60 & & N55 & HEM 300 & $8 \%$ & 20 & 60 \\
\hline & N24 & HEM 140 & $2 \%$ & 20 & 70 & & N56 & HEM 300 & $8 \%$ & 20 & 70 \\
\hline \multirow{4}{*}{ G7 } & $\mathrm{N} 25$ & HEM 140 & $2 \%$ & 24 & 40 & \multirow{4}{*}{ G15 } & N57 & HEM 300 & $8 \%$ & 24 & 40 \\
\hline & N26 & HEM 140 & $2 \%$ & 24 & 50 & & N58 & HEM 300 & $8 \%$ & 24 & 50 \\
\hline & N27 & HEM 140 & $2 \%$ & 24 & 60 & & N59 & HEM 300 & $8 \%$ & 24 & 60 \\
\hline & N28 & HEM 140 & $2 \%$ & 24 & 70 & & N60 & HEM 300 & $8 \%$ & 24 & 70 \\
\hline \multirow{4}{*}{ G8 } & N29 & HEM 140 & $2 \%$ & 30 & 40 & \multirow{4}{*}{ G16 } & N61 & HEM 300 & $8 \%$ & 30 & 40 \\
\hline & N30 & HEM 140 & $2 \%$ & 30 & 50 & & N62 & HEM 300 & $8 \%$ & 30 & 50 \\
\hline & N31 & HEM 140 & $2 \%$ & 30 & 60 & & N63 & HEM 300 & $8 \%$ & 30 & 60 \\
\hline & N32 & HEM 140 & $2 \%$ & 30 & 70 & & N64 & HEM 300 & $8 \%$ & 30 & 70 \\
\hline
\end{tabular}

Modellenen elemanlara ait yapısal çelik ve donatı çeliğinin malzeme özellikleri Tablo 2 ve Şekil 5.a'da verilmiştir. Beton malzemesine ait değeler ise poisson oranı $(v=0.2)$ ve elastisite modülü ise aşağıdaki Eşt. 1'deki denklem ile hesaplanmıştır [1].

$\mathrm{E}_{\mathrm{c}}=0.043 \mathrm{w}_{\mathrm{c}}^{1.5} \sqrt{\mathrm{f}_{\mathrm{ck}}}$ 


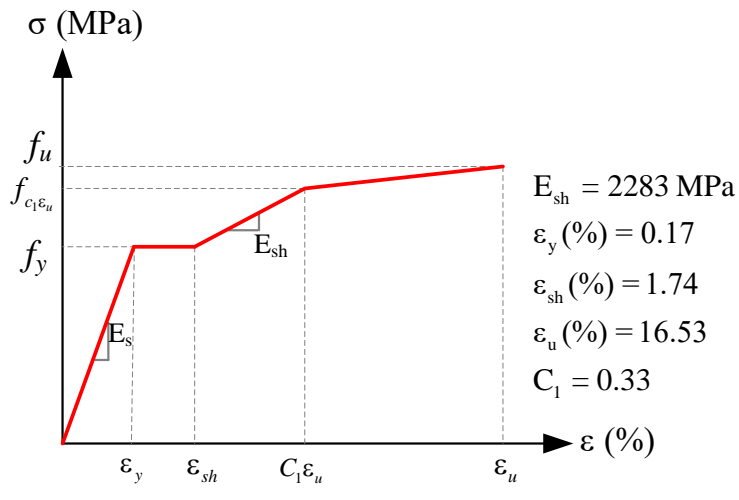

a)

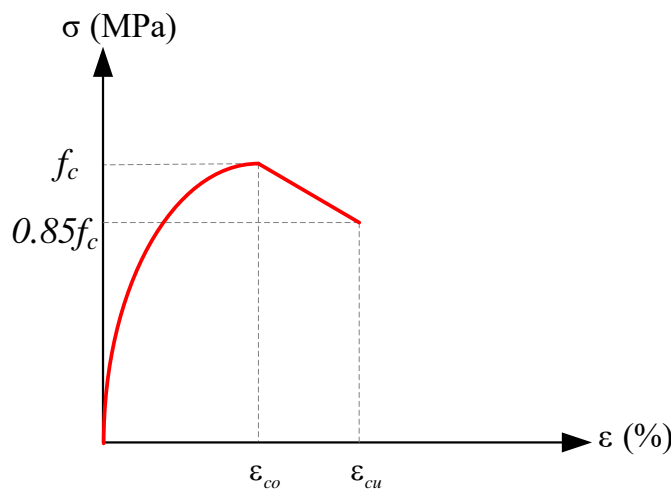

b)

Şekil 5. Gerilme-şekil değiştirme eğrisi a) Çelik [23] b) Beton [24]

Burada beton elastisite modülü $E_{c}$, birim hacim ağırlığı $\left(w_{c}=2400 \mathrm{~kg} \mathrm{~m}^{-3}\right)$ ve karakteristik basınç dayanımı $f_{\text {ck }}$ olarak ifade edilmiş olup beton malzemesine ait gerilme-şekil değiştirme $(\sigma-\varepsilon)$ eğrileri Şekil 5.b'de gösterilmiştir.

Tablo 2. Çelik malzeme özellikleri

\begin{tabular}{cccccc}
\hline Malzeme & $\begin{array}{c}\mathbf{E}_{\mathbf{s}} \\
(\mathrm{MPa})\end{array}$ & $\begin{array}{c}\mathbf{w}_{\mathbf{c}} \\
\left(\mathrm{kg} \mathrm{m}^{-3}\right)\end{array}$ & $\mathbf{v}$ & $\begin{array}{c}\mathbf{f}_{\mathbf{y}} \\
(\mathrm{MPa})\end{array}$ & $\begin{array}{c}\mathbf{f}_{\mathbf{u}} \\
(\mathrm{MPa})\end{array}$ \\
\hline S355 & 200000 & 7850 & 0.3 & 355 & 490 \\
B500C & 200000 & 7850 & 0.3 & 500 & 550 \\
\hline
\end{tabular}

Şekil 5.b'de verilen sargısız beton malzemesine ait gerilme-şekil değiştirme $(\sigma-\varepsilon)$ eğrisi olarak Hognestad [24] tarafından önerilen model kullanılmıştır. Hognestad [24] modelinde, betonun $(\sigma-\varepsilon)$ ilişkisi iki kısım olarak tanımlanmaktadır. Hognestad [24] modelinde yer alan parabolik ve doğrusal kısmı ifade eden denklemler sırasıyla Eşt. 2 ve Eşt. 3'te yer almaktadır. Modelde maksimum gerilmenin silindir basınç dayanımının \%85'i olduğu kabul edilmiştir. Burada maksimum gerilmeye karşıllk gelen birim kısalma değeri, $\varepsilon \mathrm{co}=2 \mathrm{fc} /$ Ec olarak hesaplanmıştır [6]. Kırılmaya karşılık gelen maksimum birim deformasyon değeri ise $\varepsilon \mathrm{cu}=0,004$ olarak kabul edilmektedir [25].

$$
\begin{aligned}
& \sigma_{\mathrm{c}}=\mathrm{f}_{\mathrm{c}}\left[\frac{2 \varepsilon_{\mathrm{c}}}{\varepsilon_{\mathrm{co}}}-\left(\frac{\varepsilon_{\mathrm{c}}}{\varepsilon_{\mathrm{co}}}\right)^{2}\right] \\
& \sigma_{\mathrm{c}}=\mathrm{f}_{\mathrm{c}}\left[1-0.15\left(\frac{\varepsilon_{\mathrm{c}}-\varepsilon_{\mathrm{co}}}{\varepsilon_{\mathrm{cu}}-\varepsilon_{\mathrm{co}}}\right)\right]
\end{aligned}
$$

Ayrıca MATLAB programında kodlar geliştirilerek çalışmada incelenen örnekler için ÇYTHYE [1] yönetmeliğinde (Yöntem 2) için karşılıklı etki diyagramındaki A, C, D ve B noktalarının koordinatlarını hesaplanmıştır.

ÇYTHYE [1] yönetmeliğinde hassas bir eksenel kuvvet ve eğilme momenti karşıllklı etkileşim diyagramların dayanım kontrolü için yönetmeliğin 12.6.2 (Yöntem 2) esas alınarak değerlendirilebilir. 


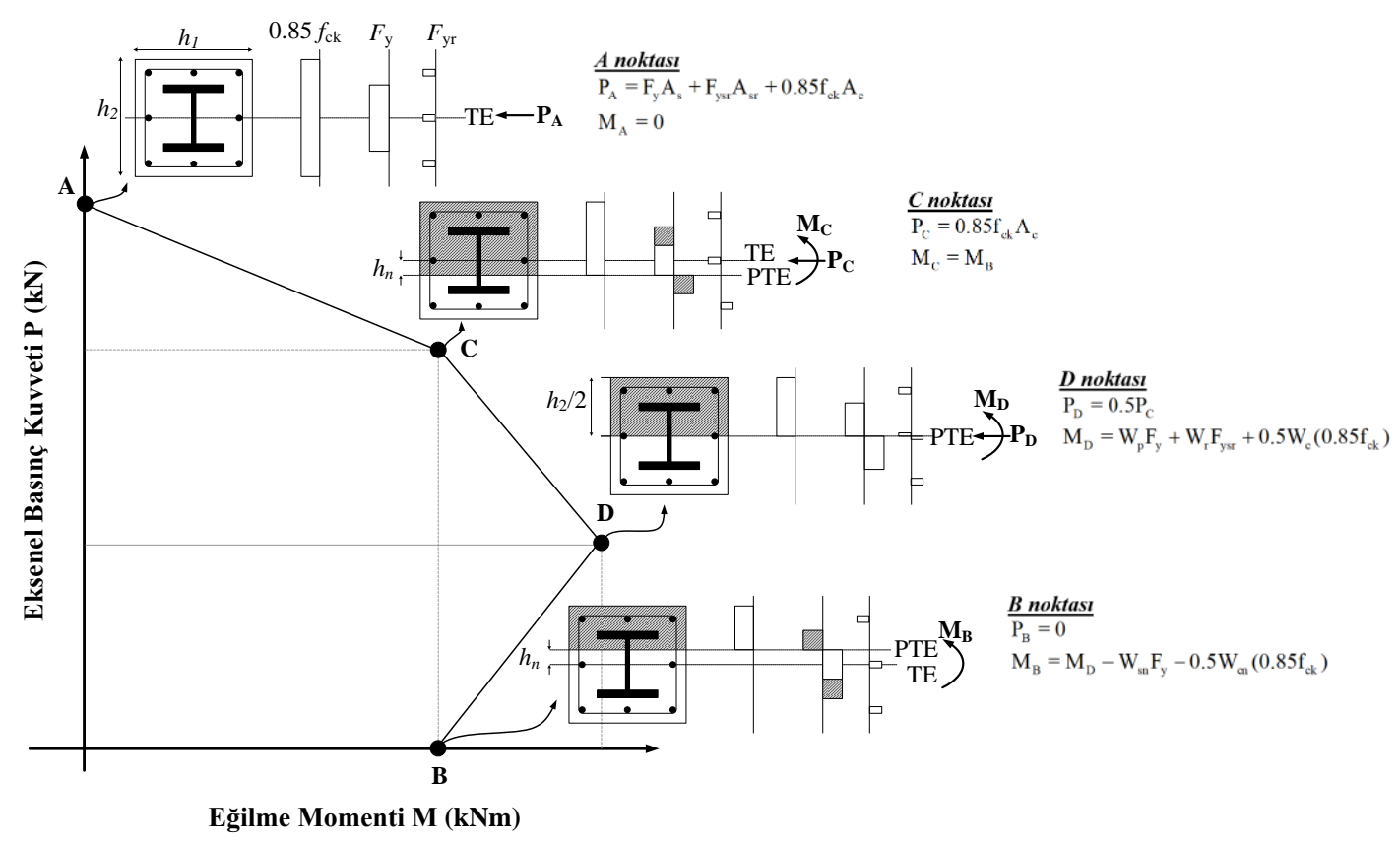

Şekil 6. Kompozit elemanlar için geliştirilmiş karşslıklı etki diyagramı [1]

Bu durumda Şekil 6'da gösterilen geliştirilmiş karşılıklı etki diyagramlarının oluşturulabilmesi için, Tablo 12.2'de verilen ifadeler kullanılarak A, C, D ve B noktalarının koordinatları belirlenmektedir [1]. Şekil 6'da gösterildiği gibi geliştirilmiş karşılıklı etki diyagramlarının oluşturulabilmesi için ilgili yönetmelikte yer alan Tablo 12.2'de verilen denklemleri kullanılarak A, C, D ve B noktalarının koordinatlarını MATLAB programı kullanılarak hesaplanmıştır.

Şekil 6'da gösterilen geliştirilmiş karşılıklı etki diyagramında yer alan A, C, D ve B noktalarının $\mathrm{W}_{\mathrm{p}}$, $\mathrm{W}_{\mathrm{c}}$ ve $\mathrm{W}_{\mathrm{r}}$ ifadeleri çelik kesit, beton ve boyuna donatı kesitine ait plastik mukavemet momentleridir. $\mathrm{W}_{\mathrm{sn}}$ ve $\mathrm{W}_{\mathrm{cn}}$ ise Şekil 6'da gösterildiği gibi $h_{\mathrm{n}}$ bölgesi içindeki çelik kesit ve beton kesitine ait plastik mukavemet momentini ifade etmektedir.

ÇYTHYE [1] yönetmeliğinde çelik gömmeli kompozit kolon basınç tasarım dayanımları aşağıdaki gibidir [1];

$$
\begin{aligned}
& \frac{P_{n o}}{P_{e}} \leq 2.25 \quad \text { için } \quad P_{n}=P_{n o}\left[0.658^{\frac{P_{n o}}{P_{e}}}\right] \\
& \frac{P_{n o}}{P_{e}}>2.25 \quad \text { için } P_{n}=0.877 P_{e} \\
& P_{n o}=F_{y} A_{s}+F_{y s r} A_{s r}+0.85 f_{c k} A_{c} \\
& P_{e}=\frac{\pi^{2}\left(E_{e f}\right)}{\left(L_{c}\right)^{2}} \\
& E_{e f}=E_{s} I_{s}+E_{s r} I_{s r}+C_{1} E_{c} I_{c} \\
& C_{1}=0.25+3\left(\frac{A_{s}+A_{s r}}{A_{g}}\right)
\end{aligned}
$$


$\mathrm{P}_{\mathrm{ys}}=\mathrm{F}_{\mathrm{y}} \mathrm{A}_{\mathrm{s}}$

$\delta=\frac{\mathrm{P}_{\mathrm{ys}}}{\mathrm{P}_{\mathrm{no}}}$

Burada sırasıyla yapısal çeliğin elastisite modülü, akma dayanımı, enkesit alanı ve atalet momenti $\left(\mathrm{E}_{s}\right.$, $\left.\mathrm{F}_{\mathrm{y}}, \mathrm{A}_{\mathrm{s}}, \mathrm{I}_{\mathrm{s}}\right)$, beton çeliğin elastisite modülü, akma dayanımı, enkesit alanı ve atalet momenti $\left(\mathrm{E}_{\mathrm{sr}}, \mathrm{F}_{\mathrm{ysr}}, \mathrm{A}_{\mathrm{sr}}\right.$, $\left.\mathrm{I}_{\mathrm{sr}}\right)$, betonun elastisite modülü, dayanımı, birim hacim ağırlığ 1 , enkesit alanı ve atalet momenti $\left(\mathrm{E}_{\mathrm{c}}, \mathrm{f}_{\mathrm{ck}}\right.$, $\mathrm{W}_{c}, \mathrm{~A}_{c}, \mathrm{I}_{\mathrm{c}}$ ) ve kompozit elemanın enkesit alanı, elastik burkulma yükü, etkin eğime rijitliği, burkulma boyu, burkulma katsayısı ve eleman uzunluğu $\left(\mathrm{A}_{\mathrm{g}}, \mathrm{P}_{\mathrm{e}}\right.$, EIef, $\left.\mathrm{L}_{\mathrm{c}}, \mathrm{K}, \mathrm{L}\right)$ olarak ifade edilmiştir [1].

\section{BULGULAR VE TARTIȘMA}

$\mathrm{Bu}$ çalışmada ortaya konulan altmış dört probleme ait karşılıklı etki diyagramı çizilmiş ve bu diyagramların A, C, D ve B noktalanı incelenmiştir. Ayrıca örnek bir kolon, göçene kadar yük artışı uygulanarak davranışı incelenmiş ve bazı bulgulara ulaşılmıştır.

ÇYTHYE [1] yönetmeliğine göre kompozit kolonlar için eksenel kuvvet-moment karşılıklı etki diyagramın örnek grafikleri verilmiştir (Şekil 7). Parametrik çalışmadaki altmış dört adet karşılıklı etki diyagramın sonucunda, boyuna donatı çapı ile çelik alan oranı $\left(\mathrm{A}_{s} / \mathrm{A}_{\mathrm{g}}\right)$ sabit seçildiğinde, beton sınıfı arttırılırsa eksenel yük taşıma kapasiteleri 1.33-1.62 artar iken eğilme momenti değerleri ise 1.22-1.60 kat artış göstermiştir. Beton sınıfı ile boyuna donatı çapı sabit seçildiğinde, çelik alan oranı $\left(\mathrm{A}_{\mathrm{s}} / \mathrm{Ag}_{\mathrm{g}}\right)$ arttırılırsa eksenel yük taşıma kapasiteleri 1.29-1.55 artar iken eğilme momenti değerleri ise 1.57-2.14 kat artış göstermiştir. Çelik alan oranı $\left(\mathrm{A}_{\mathrm{s}} / \mathrm{A}_{\mathrm{g}}\right)$ oranı ile beton sınıfı sabit seçildiğinde, boyuna donatı çap1 arttırılırsa eksenel yük taşıma kapasiteleri 1.05-1.13 artar iken eğilme momenti değerleri ise 1.11- 1.32 kat artı̧̧ göstermiştir.

ÇYTHYE [1] yönetmeliğinde Eşt. 4'te tanımlanan formüllerle tasarım dayanımları MATLAB programı yardımıyla hesaplanmıştır. ANSYS programında modellenen çelik gömmeli kompozit kolonların basınç dayanımları ise hesaplanarak karşılaştırılmıştır (Tablo 3).

Ayrıca Eşt. 10'da tanımlanan denklem kullanılarak çelik katkı oranı $(\delta)$ tüm kompozit kolonlar için hesaplanmıştır. Çelik katkı oranı, $0.2 \leq \delta \leq 0.9$ arasında olduğunda kompozit kolon, 0.2 'den küçük ise betonarme kolon ve 0.9 'dan büyük ise çelik kolon gibi davranacağı belirtilmiştir [26]. Ancak kompozit kolonlarda çelik alan oranı minimum \%1 olması gerektiği belirtilmektedir [1].

Bu nedenle ÇYTHYE [1] yönetmeliğine çelik gömmeli kompozit kolonlarda çelik alan oranı \%1 ve \%2 olduğunda $\delta<0.2$ ' den küçük ve betonarme kolon gibi davranacağı, çelik alan oranı $\% 4$ ve $\% 8$ olduğunda ise $0.2 \leq \delta \leq 0.9$ arasında kompozit kolon gibi davranacağı görülmektedir (Tablo 3 ). 

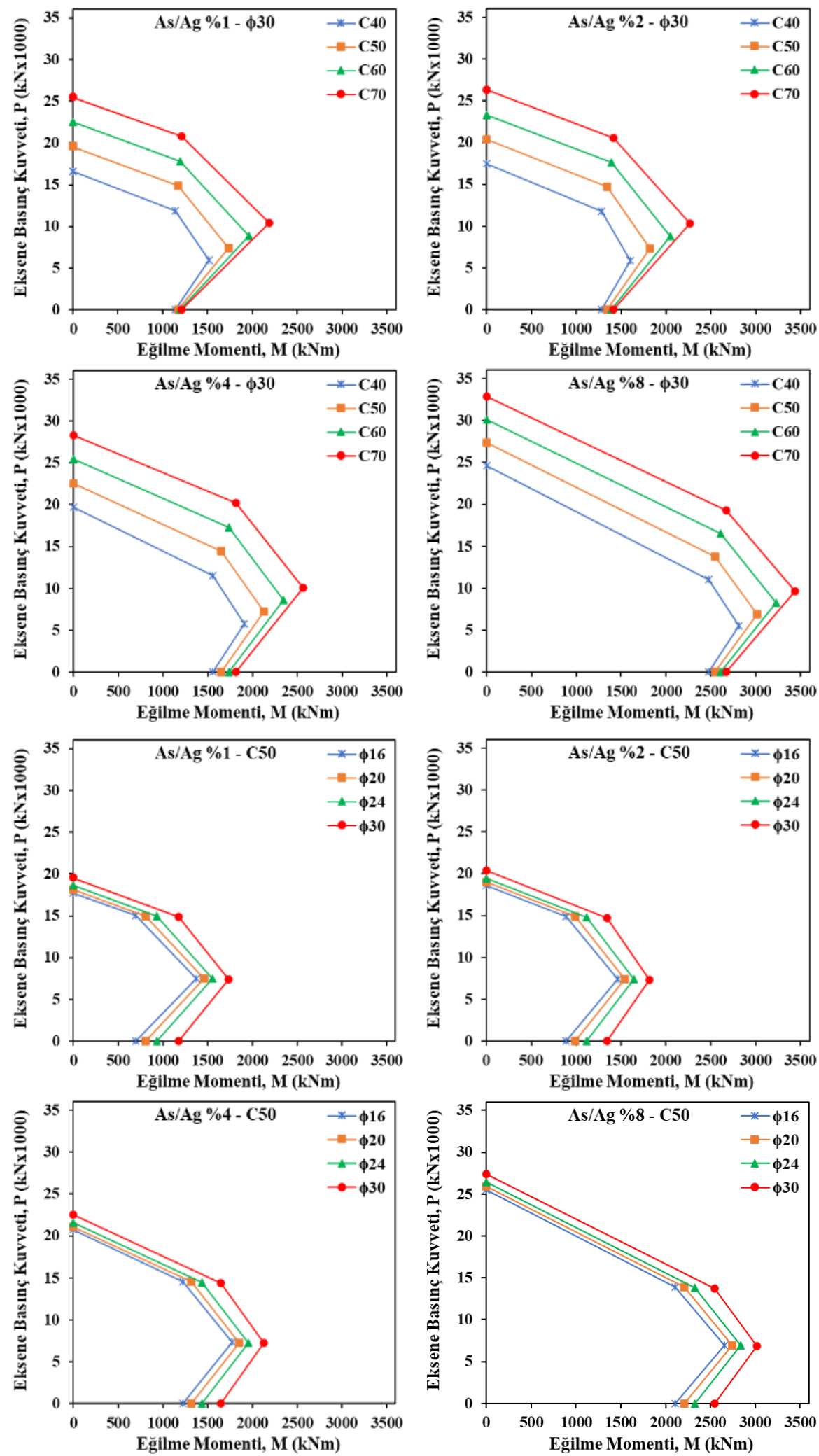

Şekil 7. Kompozit kolonlar için eksenel kuvvet-moment karşıllkll etki diyagramları 

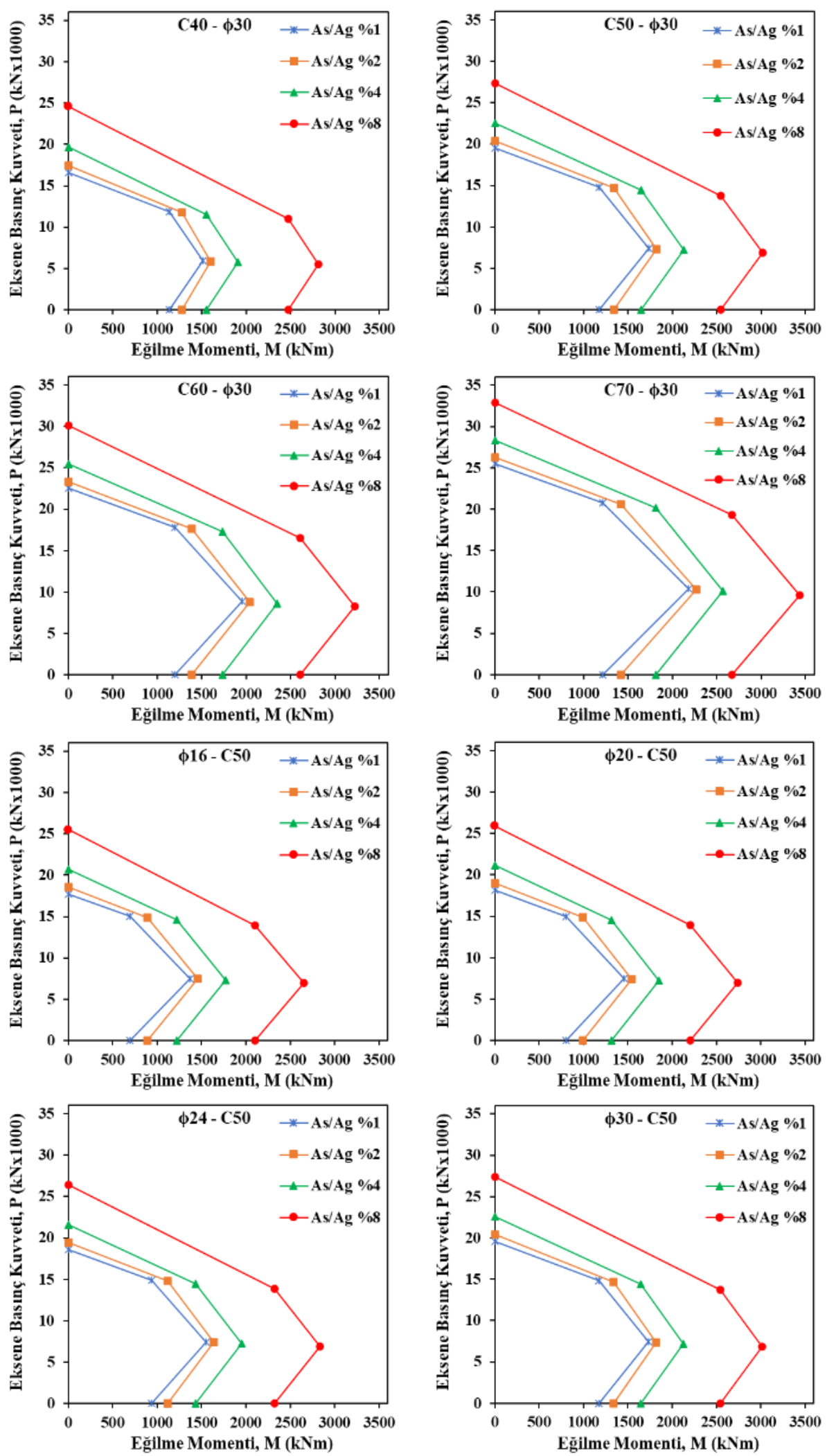

Şekil 7. (devam) Kompozit kolonlar için eksenel kuvvet-moment karşıllklı etki diyagramları 
Tablo 3. Çelik gömmeli kompozit kolon dayanımlarının tasarım dayanımları ile karşılaştıılması

\begin{tabular}{|c|c|c|c|c|c|c|c|c|c|c|c|c|}
\hline \multirow[b]{2}{*}{ Grup } & \multirow[b]{2}{*}{ Numune } & \multirow[b]{2}{*}{ Kesit Tipi } & \multirow[b]{2}{*}{$\mathbf{A}_{\mathrm{s}} / \mathbf{A}_{\mathrm{g}}$} & \multirow{2}{*}{$\begin{array}{c}\text { Boyuna } \\
\text { Donatı } \\
(\mathrm{mm})\end{array}$} & \multirow{2}{*}{$\begin{array}{c}\mathbf{f}_{\mathbf{c k}} \\
(M p a)\end{array}$} & \multirow[b]{2}{*}{$\delta$} & \multicolumn{3}{|c|}{ ÇYTHYE [1] } & \multicolumn{2}{|c|}{ ANSYS [2] } & \\
\hline & & & & & & & $\begin{array}{l}\boldsymbol{P}_{\text {no }} \\
(k N)\end{array}$ & $\begin{array}{c}\boldsymbol{P}_{\mathbf{e}} \\
(k N)\end{array}$ & 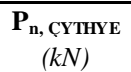 & $\begin{array}{c}\mathbf{P}_{\mathbf{n}, \text { ANSYS }} \\
(k N)\end{array}$ & $\begin{array}{c}\mathbf{U}_{\mathbf{z}} \\
(\mathrm{mm})\end{array}$ & $\overline{\mathbf{P}_{\text {CYTHYE }}}$ \\
\hline & N1 & HEM 100 & $1 \%$ & 16 & 40 & 0.13 & 14697 & 133994 & 14038 & 15200 & -7.96 & 1.08 \\
\hline G1 & $\mathrm{N} 2$ & HEM 100 & $1 \%$ & 16 & 50 & 0.11 & 17698 & 147643 & 16832 & 17280 & -7.82 & 1.03 \\
\hline U1 & N3 & HEM 100 & $1 \%$ & 16 & 60 & 0.09 & 20699 & 159983 & 19608 & 18875 & -7.81 & 0.96 \\
\hline & $\mathrm{N} 4$ & HEM 100 & $1 \%$ & 16 & 70 & 0.08 & 23701 & 171331 & 22367 & 20962 & -7.83 & 0.94 \\
\hline & N5 & HEM 100 & $1 \%$ & 20 & 40 & 0.13 & 15119 & 145768 & 14477 & 15747 & -8.15 & 1.09 \\
\hline & N6 & HEM 100 & $1 \%$ & 20 & 50 & 0.1 & 18112 & 159695 & 17273 & 17930 & -8.08 & 1.04 \\
\hline $\mathrm{G} 2$ & N7 & HEM 100 & $1 \%$ & 20 & 60 & 0.09 & 21106 & 172287 & 20051 & 19575 & -7.93 & 0.98 \\
\hline & N8 & HEM 100 & $1 \%$ & 20 & 70 & 0.08 & 24099 & 183866 & 22813 & 21570 & -7.88 & 0.95 \\
\hline & N9 & HEM 100 & $1 \%$ & 24 & 40 & 0.12 & 15634 & 159872 & 15007 & 16490 & -8.34 & 1.10 \\
\hline & N10 & HEM 100 & $1 \%$ & 24 & 50 & 0.1 & 18618 & 174138 & 17803 & 18763 & -8.32 & 1.05 \\
\hline G3 & N11 & HEM 100 & $1 \%$ & 24 & 60 & 0.09 & 21602 & 187035 & 20583 & 20508 & -8.19 & 1.00 \\
\hline & N12 & HEM 100 & $1 \%$ & 24 & 70 & 0.08 & 24586 & 198895 & 23347 & 22675 & -8.21 & 0.97 \\
\hline & N13 & HEM 100 & $1 \%$ & 30 & 40 & 0.11 & 16583 & 185167 & 15973 & 17280 & -8.21 & 1.08 \\
\hline & N14 & HEM 100 & $1 \%$ & 30 & 50 & 0.1 & 19550 & 200049 & 18766 & 19680 & -8.28 & 1.05 \\
\hline G4 & N15 & HEM 100 & $1 \%$ & 30 & 60 & 0.08 & 22516 & 213504 & 21544 & 21500 & -8.21 & 1.00 \\
\hline & N16 & HEM 100 & $1 \%$ & 30 & 70 & 0.07 & 25483 & 225877 & 24308 & 23625 & -8.21 & 0.97 \\
\hline & N17 & HEM 140 & $2 \%$ & 16 & 40 & 0.18 & 15577 & 144121 & 14888 & 16127 & -8.13 & 1.08 \\
\hline C5 & N18 & HEM 140 & $2 \%$ & 16 & 50 & 0.15 & 18555 & 158773 & 17669 & 18300 & -8.08 & 1.04 \\
\hline Us & N19 & HEM 140 & $2 \%$ & 16 & 60 & 0.13 & 21532 & 172019 & 20433 & 19980 & -7.97 & 0.98 \\
\hline & $\mathrm{N} 20$ & HEM 140 & $2 \%$ & 16 & 70 & 0.12 & 24510 & 184200 & 23183 & 22010 & -7.94 & 0.95 \\
\hline & $\mathrm{N} 21$ & HEM 140 & $2 \%$ & 20 & 40 & 0.18 & 15998 & 155859 & 15326 & 16540 & -8.23 & 1.08 \\
\hline C6 & $\mathrm{N} 22$ & HEM 140 & $2 \%$ & 20 & 50 & 0.15 & 18969 & 170784 & 18107 & 18635 & $\begin{array}{l}-8.11 \\
\end{array}$ & 1.03 \\
\hline Go & $\mathrm{N} 23$ & HEM 140 & $2 \%$ & 20 & 60 & 0.13 & 21939 & 184278 & 20872 & 20312 & -8.01 & 0.97 \\
\hline & $\mathrm{N} 24$ & HEM 140 & $2 \%$ & 20 & 70 & 0.12 & 24909 & 196687 & 23623 & 22282 & -7.96 & 0.94 \\
\hline & $\mathrm{N} 25$ & HEM 140 & $2 \%$ & 24 & 40 & 0.17 & 16514 & 169919 & 15856 & 17340 & -8.47 & 1.09 \\
\hline G7 & $\mathrm{N} 26$ & HEM 140 & $2 \%$ & 24 & 50 & 0.15 & 19474 & 185178 & 18636 & 19600 & -8.45 & 1.05 \\
\hline or & N27 & HEM 140 & $2 \%$ & 24 & 60 & 0.13 & 22435 & 198973 & 21401 & 21550 & -8.46 & 1.01 \\
\hline & $\mathrm{N} 28$ & HEM 140 & $2 \%$ & 24 & 70 & 0.11 & 25396 & 211659 & 24152 & 23675 & -8.45 & 0.98 \\
\hline & $\mathrm{N} 29$ & HEM 140 & $2 \%$ & 30 & 40 & 0.16 & 17462 & 195137 & 16820 & 18345 & -8.44 & 1.09 \\
\hline G8 & N30 & HEM 140 & $2 \%$ & 30 & 50 & 0.14 & 20406 & 211003 & 19596 & 20580 & -8.39 & 1.05 \\
\hline G8 & N31 & HEM 140 & $2 \%$ & 30 & 60 & 0.12 & 23349 & 225347 & 22358 & 22637 & -8.46 & 1.01 \\
\hline & N32 & HEM 140 & $2 \%$ & 30 & 70 & 0.11 & 26293 & 238538 & 25107 & 24762 & -8.44 & 0.99 \\
\hline & $\mathrm{N} 33$ & HEM 220 & $4 \%$ & 16 & 40 & 0.3 & 17785 & 173608 & 17039 & 18630 & -8.38 & 1.09 \\
\hline & N34 & HEM 220 & $4 \%$ & 16 & 50 & 0.26 & 20705 & 190738 & 19785 & 20930 & -8.41 & 1.06 \\
\hline G9 & N35 & HEM 220 & $4 \%$ & 16 & 60 & 0.23 & 23624 & 206226 & 22518 & 22650 & -8.27 & 1.01 \\
\hline & N36 & HEM 220 & $4 \%$ & 16 & 70 & 0.2 & 26543 & 220468 & 25239 & 24640 & -8.21 & 0.98 \\
\hline & N37 & HEM 220 & $4 \%$ & 20 & 40 & 0.29 & 18207 & 185248 & 17473 & 19020 & -8.39 & 1.09 \\
\hline G10 & N38 & HEM 220 & $4 \%$ & 20 & 50 & 0.25 & 21119 & 202642 & 20217 & 21400 & -8.49 & 1.06 \\
\hline Gio & N39 & HEM 220 & $4 \%$ & 20 & 60 & 0.22 & 24030 & 218367 & 22949 & 23340 & -8.49 & 1.02 \\
\hline & $\mathrm{N} 40$ & HEM 220 & $4 \%$ & 20 & 70 & 0.2 & 26942 & 232827 & 25668 & 25500 & -8.52 & 0.99 \\
\hline & $\mathrm{N} 41$ & HEM 220 & $4 \%$ & 24 & 40 & 0.28 & 18722 & 199194 & 18000 & 19570 & -8.41 & 1.09 \\
\hline G11 & $\mathrm{N} 42$ & HEM 220 & $4 \%$ & 24 & 50 & 0.25 & 21624 & 216906 & 20741 & 21920 & -8.47 & 1.06 \\
\hline G11 & $\mathrm{N} 43$ & HEM 220 & $4 \%$ & 24 & 60 & 0.22 & 24527 & 232920 & 23469 & 23880 & $\begin{array}{l}-8.49 \\
\end{array}$ & 1.02 \\
\hline & $\mathrm{N} 44$ & HEM 220 & $4 \%$ & 24 & 70 & 0.19 & 27429 & 247646 & 26186 & 26025 & -8.51 & 0.99 \\
\hline & $\mathrm{N} 45$ & HEM 220 & $4 \%$ & 30 & 40 & 0.27 & 19671 & 224204 & 18962 & 20525 & -8.41 & 1.08 \\
\hline G12 & $\mathrm{N} 46$ & HEM 220 & $4 \%$ & 30 & 50 & 0.24 & 22556 & 242500 & 21695 & 22900 & -8.49 & 1.06 \\
\hline 012 & $\mathrm{~N} 47$ & HEM 220 & $4 \%$ & 30 & 60 & 0.21 & 25441 & 259040 & 24416 & 24875 & -8.51 & 1.02 \\
\hline & $\mathrm{N} 48$ & HEM 220 & $4 \%$ & 30 & 70 & 0.19 & 28326 & 274251 & 27127 & 27048 & -8.54 & 1.00 \\
\hline & $\mathrm{N} 49$ & HEM 300 & $8 \%$ & 16 & 40 & 0.47 & 22719 & 250483 & 21873 & 23430 & -8.07 & 1.07 \\
\hline G13 & N50 & HEM 300 & $8 \%$ & 16 & 50 & 0.42 & 25508 & 272963 & 24529 & 25534 & -8.02 & 1.04 \\
\hline G13 & N51 & HEM 300 & $8 \%$ & 16 & 60 & 0.38 & 28296 & 293286 & 27177 & 27302 & -8.21 & 1.00 \\
\hline & N52 & HEM 300 & $8 \%$ & 16 & 70 & 0.35 & 31085 & 311976 & 29815 & 29541 & -8.18 & 0.99 \\
\hline & N53 & HEM 300 & $8 \%$ & 20 & 40 & 0.47 & 23141 & 261893 & 22301 & 23900 & -8.16 & 1.07 \\
\hline & N54 & HEM 300 & $8 \%$ & 20 & 50 & 0.42 & 25922 & 284608 & 24952 & 26128 & -8.22 & 1.05 \\
\hline G14 & N55 & HEM 300 & $8 \%$ & 20 & 60 & 0.38 & 28703 & 305145 & 27595 & 27931 & -8.19 & 1.01 \\
\hline & N56 & HEM 300 & $8 \%$ & 20 & 70 & 0.34 & 31484 & 324030 & 30229 & 29900 & -8.17 & 0.99 \\
\hline & N57 & HEM 300 & $8 \%$ & 24 & 40 & 0.46 & 23656 & 275561 & 22821 & 24450 & -8.17 & 1.07 \\
\hline & N58 & HEM 300 & $8 \%$ & 24 & 50 & 0.41 & 26428 & 298564 & 25466 & 26716 & -8.25 & 1.05 \\
\hline Gi5 & N59 & HEM 300 & $8 \%$ & 24 & 60 & 0.37 & 29199 & 319359 & 28103 & 28486 & -8.19 & 1.01 \\
\hline & N60 & HEM 300 & $8 \%$ & 24 & 70 & 0.34 & 31971 & 338483 & 30732 & 30512 & -8.21 & 0.99 \\
\hline & N61 & HEM 300 & $8 \%$ & 30 & 40 & 0.44 & 24605 & 300075 & 23775 & 25340 & -8.12 & 1.07 \\
\hline & N62 & HEM 300 & $8 \%$ & 30 & 50 & 0.39 & 27359 & 323602 & 26408 & 27595 & -8.18 & 1.04 \\
\hline G10 & N63 & HEM 300 & $8 \%$ & 30 & 60 & 0.36 & 30113 & 344871 & 29033 & 29485 & -8.21 & 1.02 \\
\hline & N64 & HEM 300 & $8 \%$ & 30 & 70 & 0.33 & 32868 & 364431 & 31650 & 31515 & -8.22 & 1.00 \\
\hline & & & & & & & & & & Ortala & ma: & 1.03 \\
\hline
\end{tabular}




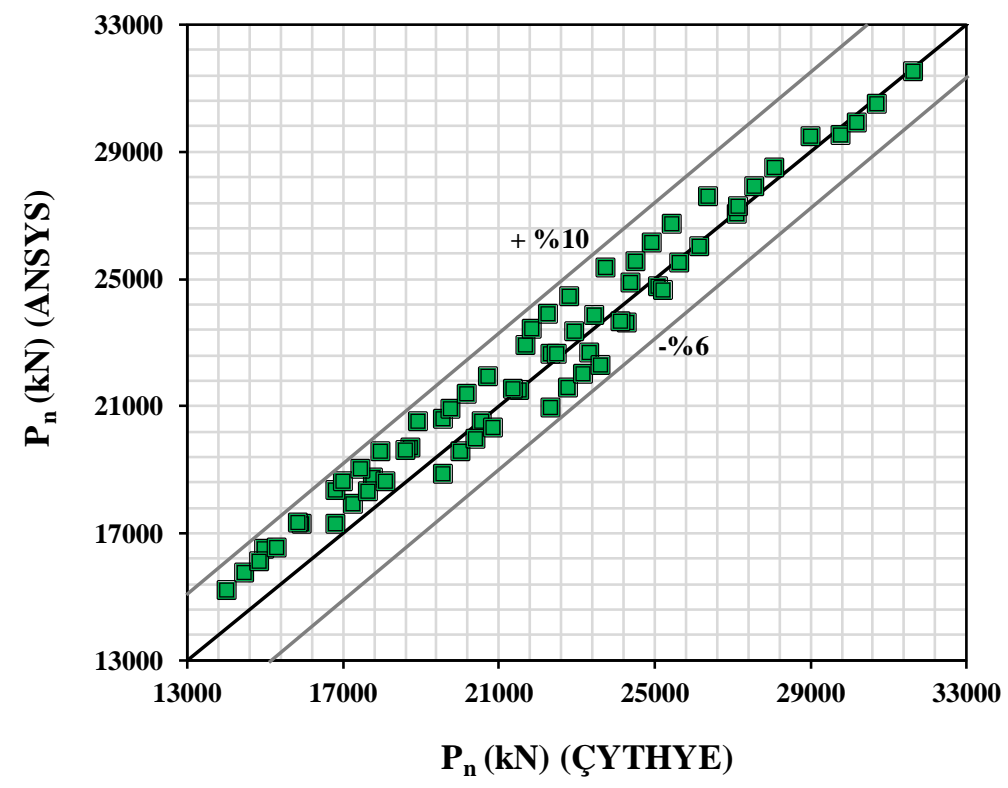

Şekil 8. Eksenel yük kapasitesi ÇYTHYE [1] ve ANSYS [2] saylsal karşılaştırılması

Kompozit kolona ait 64 adet parametrik çalışmada elde edilen en büyük eksenel yük kapasitesinin ÇYTHYE [1] ve ANSYS [2] sayısal karşılaştırılmasında bu oranlar -\%6 ile $+\% 10$ aralığında yakınsadığı görülmüştür (Şekil 8).
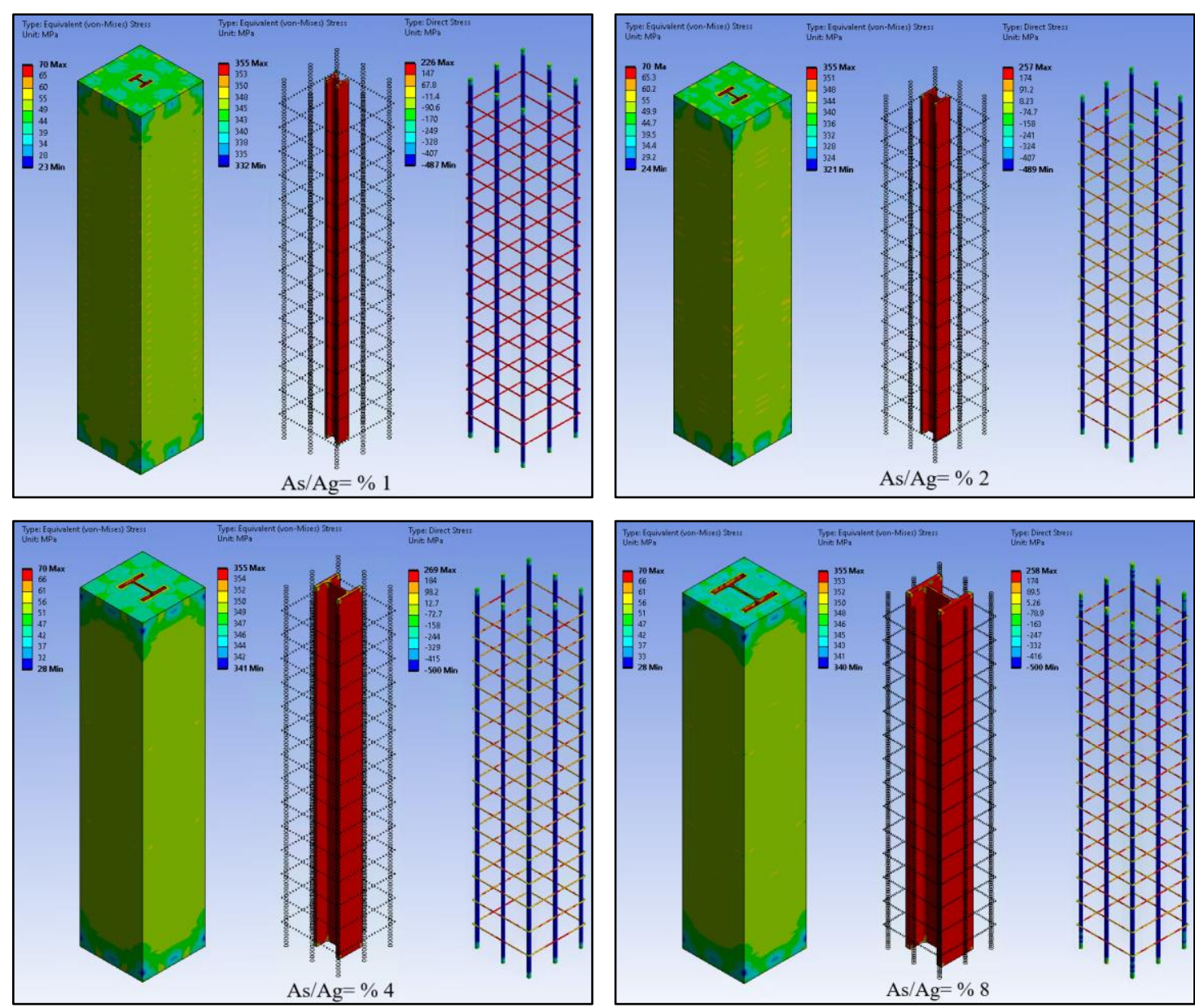

Şekil 9. Beton sınıfi C70 ve boyuna donatı $\phi 30$ 'daki çelik gömmeli kompozit kolona ait malzemelerin gerilme davranışları 


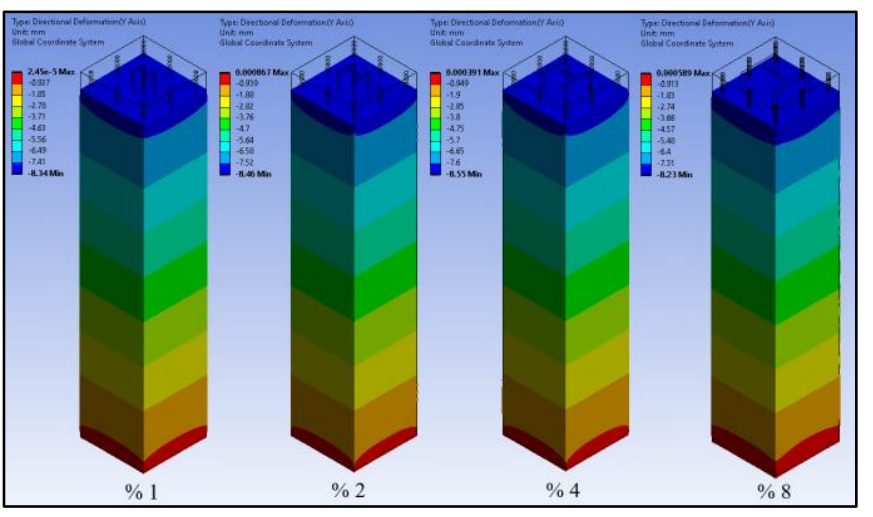

a)

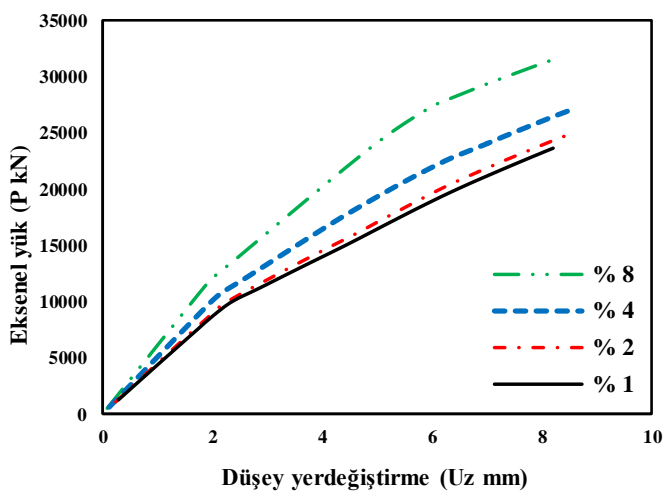

b)

Şekil 10. Beton sinifi C70 ve boyuna donatı $\phi 30$ 'daki çelik gömmeli kompozit kolona ait a) ANSYS sonuçları b) Kuvvet-düşey yer değiştirme grafiği

Parametrik çalışmadaki altmış dört adet çelik gömmeli kompozit kolona ait analizde, üst levhaya yük artışları uygulanarak göçene kadar doğrusal olmayan analizler yapılmıştır. Bu analizler sonucunda göçme durumuna geldiğinde tüm kompozit kolonlardaki çelik profillerin tamamen akma dayanımına ulaştığı görülmüştür.

Örneğin beton sınıfi $C 70$, boyuna donat1 $\phi 30$ ve $A_{s} / A_{g}$ oranı \%1-2-4-8 olan çelik gömmeli kompozit kolona ait olan gerilme davranışları incelenmiştir. Kompozit kolonlar eksenel yük altında göçme durumuna ulaştığında, yapısal çelik profilin ve boyuna donatı çeliğin akma sınırına yaklaştığı görülmüştür (Şekil 9). Ayrıca düşey yer değiştirme Şekil 10.a'da ve Tablo 3'te verilmiştir. Kompozit kolonların kuvvet-deplasman grafikleri de Şekil 10.b'de verilmiştir. Diğer kompozit kolon elemanlarında benzer şekilde davrandığı görülmüştür.

\section{SONUC}

$\mathrm{Bu}$ çalışmada iki ucu mafsallı kompozit kolonların, aynı kesit boyutları 600x600 mm, enine donatı çapları $\phi 10 / 200 \mathrm{~mm}$ ve kolon yüksekliği $3000 \mathrm{~mm}$, farklı boyuna donatı çapı, beton sınıfı ve çelik alan oranına sahip kompozit kolonların, tasarım basınç dayanımları ve eksenel kuvvet-moment eğrilerin davranışı incelenmiştir. Bu davranışa etki eden yapısal çelik alan oranı, beton dayanımı ve boyuna donatı oranı gibi parametrelerin etkisini araştırmak için ÇYTHYE [1] yönetmeliği kullanılarak toplamda altmış dört adet analiz yapılmıştır. Bu analizleri üç boyutlu ANSYS programı kullanılarak doğrusal olmayan (nonlinear) analizler yapılarak ÇYTHYE [1] yönetmeliği ile karşılaştırmalar yapılmıştır. Yapılan analizler sonucunda elde edilen bulgular aşağıdaki gibi özetlenmiştir;

Boyuna donatı çapı ile çelik alan oranı $\left(\mathrm{A}_{\mathrm{s}} / \mathrm{A}_{\mathrm{g}}\right)$ sabit seçildiğinde, beton sınıfi arttırılırsa eksenel yük taşıma kapasiteleri 1.33-1.62 artar iken eğilme momenti değerleri ise 1.22- 1.60 kat artış göstermiştir. Beton sınıfı ile boyuna donatı çapı sabit seçildiğinde, çelik alan oranı $\left(\mathrm{A}_{s} / \mathrm{A}_{\mathrm{g}}\right)$ arttırılırsa eksenel yük taşıma kapasiteleri 1.29-1.55 artar iken eğilme momenti değerleri ise 1.57- 2.14 kat artış göstermiştir. Çelik alan oranı $\left(\mathrm{A}_{\mathrm{s}} / \mathrm{A}_{\mathrm{g}}\right)$ oranı ile beton sınıfı sabit seçildiğinde, boyuna donatı çapı arttırılırsa eksenel yük taşıma kapasiteleri 1.05-1.13 artar iken eğilme momenti değerleri ise 1.11-1.32 kat artı̧̧ göstermiştir. Çelik gömmeli kompozit kolondaki çelik profil tamamen akma dayanımına ulaşmış olup; inelastik davranış göstermiştir. Yapısal çelik için ANSYS den hesaplanan yük ile yönetmelikte hesaplanan en büyük eksenel yük oranları 0.94-1.10 aralığında iken ortalama ise 1.03 olarak bulunmuştur. ÇYTHYE [1] yönetmeliğine göre yapısal çelik alan oran \%1'den büyük ise kompozit kolon olarak tasarlanmaktadır. Ancak Eurocode 4 [26] yönetmeliğine göre grup 1- 8 betonarme kolon davranış1 gösterirken grup 9-16 kompozit kolon davranış1 sergilediği görülmüştür. 
Sonlu elemanlar ile analiz yapılırken seçilen eleman tipi-SOLID185'in analitik çalışma ile bulunan sonuçlarla uyumlu olduğu görülmüştür. Bu tip bir çalışma yürütülürken, seçilecek sonlu eleman tipinin önemli olduğu ve modelin malzeme, geometri ya da hem malzeme hem de geometri bakımından lineer olmayan davranış açısından irdelenmesi gerekmektedir.

\section{KAYNAKLAR}

[1] Çelik Yapıların Tasarım, Hesap ve Yapım Esaslarına Dair Yönetmelik, 2016.

[2] ANSYS, ANSYS User’s Manual Revision 19.0, ANSYS, Inc., USA, 2019.

[3] D. Tjitradi, E. Eliatun ve S. Taufik, "3D ANSYS Numerical Modeling of Reinforced Concrete Beam Behavior under Different Collapsed Mechanisms," International Journal of Mechanics and Applications, c. 7, s. 1, ss. 14-23, 2017.

[4] S. Taufik, G. Utomo ve A. Sugianto, "Behavior of filled and encased composite column using 3D numerical modelling ANSYS," International Journal of Composite Materials, c. 8, s. 1, ss. 18-23, 2018.

[5] E. Ellobody, B. Young ve D. Lam D, "Eccentrically loaded concrete encased steel composite columns," Thin-Walled Structures, c. 49, s. 1, ss. 53-65, 2011.

[6] D. Ertürkme, C. Dündar ve S. Tokgöz, "Karbon Lifli Polimer Sargılı Narin Betonarme Kolonların Moment Büyütme Yöntemi ile Analizi," Çukurova Üniversitesi Mühendislik Mimarlı Fakültesi Dergisi, c. 31, s. 1, ss. 11-21, 2016.

[7] T. Stolarski, Y. Nakasone ve S. Yoshimoto, "Application of ANSYS to stress analysis", Engineering Analysis with ANSYS Software, Linacre house, Oxford, 1st Edition, Elsevier Butterworth, 2006, ss. 51-142.

[8] S. Taufik ve B. Tjahjono, "3D ANSYS Modeling behaviour of encased steel composite column with wide flange and hollow section," International Journal of Mechanics and Applications, c. 9, s. 1, ss. 10-18, 2019.

[9] T. Kartheek ve T.V. Das, "3D modelling and analysis of encased steel-concrete composite column using ABAQUS," Materials Today: Proceedings, c. 27, s. 2, ss. 1545-1554, 2020.

[10] K.S. Virdi ve P.J. Dowling, "The ultimate strength of composite columns in biaxial bending," Proceedings Institution of Civil Engineers, c. 55, s. 1, ss. 251-72, 1973.

[11] P.R. Munoz ve C.T. Hsu, "Behaviour of biaxially loaded concrete-encased composite columns," Journal of Structural Engineering, ASCE, c. 123, s. 9, ss. 1163-1171, 1997.

[12] C.C. Chen ve N.J. Lin, "Analytical model for predicting axial capacity and behavior of concrete encased steel composite stub columns," Journal of Constructional Steel Research, c. 62, s. 5, 424-433, 2006.

[13] E. Ellobody ve B. Young, "Numerical simulation of concrete encased steel composite columns," Journal of Constructional Steel Research, c. 67, s. 2, 211-222, 2011.

[14] B. Lai, J.Y. Richard Liew ve S. Li, "Finite element analysis of concrete-encased steel composite columns with off-center steel section," 12th International Conference on Advances in Steel-Concrete Composite Structures, ss. 27-29, 2018. 
[15] D.H Nguyen ve W.K. Hong, "An analytical model computing the flexural strength and performance of the concrete columns confined by both transverse reinforcements and steel sections," Journal of Asian Architecture and Building Engineering, c. 19, s. 6, ss. 647-66, 2020.

[16] B. Lai ve J.Y. Richard Liew, "Axial-moment interaction of high strength concrete encased steel composite columns: Design recommendation," Journal of Constructional Steel Research, c. 170, s. 7, ss. 106136, 2019.

[17] O. Düğenci, “Artı kesitli çekirdeğe sahip burkulması önlenmiş basınç çubuklarının eksenel yük altında deneysel ve numerik araştırılması," Doktora tezi, Fen Bilimler Enstitüsü, Erciyes Üniversitesi, Kayseri, Türkiye, 2015.

[18] I. Montava, R. Irles, J. Segura, J. M. Gadea ve E. Juliá "Numerical simulation of steel reinforced concrete (SRC) joints," Metals, c. 9, s. 2, ss. 131, 2019.

[19] S. Kedziora ve M. O. Anwaar, "Concrete-filled steel tubular (CFTS) columns subjected to eccentric compressive load," Proceedings of the 15th Stability of Structures Symposium, ss. 20004, 2019.

[20] F. P. M. Quevedo, R. J. Schmitz, I. B. Morsch, A. C. Filho, D. Bernaud, "Customization of a software of finite elements to analysis of concrete structures: long-term effects," Ibracon structures and materials journal, c. 11, s. 4, ss. 696-718, 2018.

[21] S. B. Krylov, V. I. Travush, A. S. Krylov ve D. V. Konin, "Contact technologies in design of reinforced concrete beams with cracks," IOP Conference Series: Materials Science and Engineering, ss. $456,2018$.

[22] ANSI/AISC 360-16-Specification for structural steel buildings. American Institute of Steel Construction (AISC), 2016.

[23] X. Yun and L. Gardner L, "Stress-strain curves for hot-rolled steels," Journal of Constructional Steel Research, c. 133, s. 6, ss. 36-46, 2017.

[24] E. Hognestad, N.W. Hanson and DMchenry, "Concrete Stress Distribution in Ultimate Stress Design,” ACI Journal, c. 27, s. 4, ss. 455-479, 1955.

[25] H.B. Özmen, M. İnel and H. Bilgin, "Sargılı beton davranışının betonarme eleman ve sistemdavranışına etkisi," Gazi Üniversitesi Mühendislik Mimarlık Fakültesi Dergisi, c. 22, s. 2, ss. 375- 383, 2007.

[26] Eurocode 4 : Design of composite steel and concrete structures-Part 1-1. General rules and rules for buildings, EN 1994-1-1, 2004. 